\title{
Pengaruh Anxiety Terhadap Intimacy Dengan Pasangan
}

\author{
Dr. Jonidius Illu, M.Th. \\ Sekolah Tinggi Teologi Injili Arastamar (SETIA) Jakarta \\ joillu@sttsetia.ac.id
}

\begin{abstract}
Abstrak
Dalam suatu keluarga dibutuhkan intimacy guna membangun hubungan yang sehat. Hubungan yang sehat dalam berintimacy adalah suatu hubungan yang masing-masing pasangan mengalami perubahan hidup dan saling membantu demi perbaikan secara bersama-sama, sehingga tercapainya keluarga yang bahagia. Penulis membahas pengaruh anxiety terhadap intimacy karena ibu x menunjukkan gejala-gejala anxiety, misalnya tidak dapat tidur dengan baik, terus-menerus mengontrol suami melalui telepon karena ada kecurigaan bahwa suaminya selingkuh dan salah dalam pemakaian uang. Dari cerita ibu $\mathrm{x}$ bahwa akibatnya mereka kurang komuniksi dan tidak dapat menerima kekurangan yang satu dengan yang lain. Hal ini mengakibatkan ibu x sering mengalami sakit, kedua anaknya tidak terawat dengan baik bahkan hubungan kedua pasangan terhadap keluarga kedua belah pihak tidak harmonis.
\end{abstract}

Kata kunci: anxiety, intimacy, pasangan

\section{Pendahuluan}

Jika terjadi intimacy yang sehat dengan pasangan maka anak-anak juga akan menikmati suasana keluarga yang sehat tersebut, bahkan bukan hanya ke dalam keluarga inti tetapi juga dirasakan oleh masing-masing keluarga dari pihak laki-laki dan wanita serta bagi lingkungan. ${ }^{1}$

Menurut Les dan Leslie Parrott ${ }^{2}$ bahwa setiap pasangan takut intimacy karena takut ditolak oleh pasangan. Ia merasa anxiety jika pasangannya tidak dapat menerimanya.

Dalam sebuah keluarga, intimacy adalah hal yang penting oleh karena dengan adanya intimacy maka kedua pasangan saling berbagi dan menyatakan perasaanperasaan yang mendalam mengenai apa yang sesungguhnya terjadi dalam kehidupan. ${ }^{3}$

\section{Anxiety}

Penulis meneliti bahwa ada berbagai pengertian yang dikemukakan oleh banyak tokoh, sehingga pada bagian ini penulis hanya mengutip beberapa kutipan mengenai anxiety.

"Anxiety is basic, ubiquitous emotional experience. Its discomforting, unsettling feelings provoke the individual to seek relief4." Atau "anxiety was one of the earlier concerns for which he suggested an explanation, which he tenaciously held onto."5

\footnotetext{
1 Jurnal of Famili Psychology, October 2008, Vol. 22, no. 5, 659-666

2 Les dan Leslie Parrott, Selamatkan Pernikahan Anda Sebelum Pernikahan Itu Dimulai, (Jakarta: Immanuel, 2007), 50

${ }^{3}$ Les dan Leslie Parrott, Ketika Hal-Hal Buruk Terjadi Pada Pernikahan Yang Baik, (Batam: Interaksara, 2002), 64

${ }^{4}$ W. Walter Menninger, Coping with Anxiety, (London: Jason Aronson, 1996), 83.
} 
Anxiety dapat timbul sebagai reaksi atas 'bahaya' yang benar-benar ada maupun yang sebenarnya tidak ada (hasil dari imajinasi saja) yang seringkali disebut "freefloathing anxiety" (anxiety yang terus mengambang tanpa diketahu sebabnya). Di mana orang bersangkutan merasakan kekuatiran tanpa ia sendiri tahu sebabnya.

Seorang Psikolog bernama Elizabeth Hurlock (1978) ${ }^{6}$ mendefinisikan kekuatiran sebagai: "an uneasy mental state concerning impending or anticipated ill." Jadi di dalam pengertian ini, kekuatiran dihubungkan dengan antisipasi terhadap halhal buruk yang mungkin terjadi dikemudian hari. Di dalam pengertian ini juga dapat kita dapat lihat dari dua unsur kejiwaan, yaitu emosi dan kognisi. Kondisi mental yang kuatir adalah unsur emosi sedangkan antisipasi adalah unsur kognisi. Hurlock jauh lebih menambahkan bahwa kekuatiran "is marked by apprehension, uneasiness, and foreboding from which the individual can not escape. It is accompanied by a feeling of helplessness because the anxious person feels blocked, uneable to find a solution for problems."

Dari penjelasan di atas penulis menyimpulkan bahwa anxiety adalah perasaan kuatir, yang sering ditandai dengan reaksi tubuh atas bahaya yang dihadapi dan anxiety muncul karena bahaya yang tidak real yang bisa melumpuhkan seseorang hingga hal-hal yang biasanya dapat ia lakukan dengan baik, tidak dapat dilakukan seperti biasanya.

Collin's ${ }^{7}$ memberikan beberapa sebab mengapa seseorang pada akhirnya anxiety. Ada berbagai sebab yang mengakibatkan seseorang menjadi anxiety, antara lain:

a. karena threat yang bersifat membahayakan, self-esteem tidak ia dapatkan dari orang lain, ia terpisah dari lingkungan sosialnya, values dan juga unconscious influence.

- Muncul karena individu merasa ada sesuatu yang mengancam.

- Apa yang merupakan ancaman buat setiap individu bisa berbeda-beda

b. Karena ada konflik.

Karena ada kepentingan antara keinginan yang naturnya bertolak belakang, yaitu:

- Ada keinginan untuk mendapatkan kedua-duanya (approachapproach).

- Ragu-ragu dalam menentukan dua pilihan (approach - avoidance).

c. Karena takut

d. Kebutuhan-kebutuhan mendasarnya tidak terpenuhi.

- Kelangsungan hidup

- Survival

- Security

William Glasser ${ }^{8}$ menyatakan bahwa dua kebutuhan yang paling mendasar adalah kebutuhan untuk dicintai-mencintai serta kebutuhan untuk merasa diri berharga (self-worth) bagi orang lain dan bagi diri sendiri.

e. Psysiology. Secara psikologi dapat mempengaruhi kejiwaan.

f. Pemahaman teologis

${ }^{5}$ Seward Hiltnes, Constructive Aspects of Anxiety, (New York: Abingdon Press, 1963), 17.

6 Fanny Riany, 72.

${ }^{7}$ Collin's, Gary R. Christian Counseling, (Melbourne: Word Publishing, 1988)

8 William Glasser, Reality Therapi,( New York, Harper and Row, 1965), 9. 
Jika Allah dilihat sebagai Allah yang berkuasa, mengasihi, baik dan mengawasi sepenuhnya alam semesta, maka ada kepercayaan dan keamanan di tengahtengah pergolakan serta meyakini bahwa Allah menyediakan kebutuhankebutuhan kita di bumi membuat kita percaya sepenuhnya pada Allah sehingga kekuatiran kita akan berkurang.

Ada beberapa tipe dari anxiety ${ }^{9}$, yaitu tipe yang neurotic anxiety, tipe acute atau state anxiety, tipe yang chronic atau trait anxiety dan normal anxiety. Ibu x mengalami Tipe yang chronic atau trait anxiety, yaitu dengan beberapa ciri antara lain:

a. Kebalikan dari state anxiety, yaitu persistent, ever - present dan ada emosional tension

b. Pribadi yang anxiety ini terlihat selalu cemas setiap saat

c. Bisa menimbulkan physical illness oleh karena tubuh tidak biasa berfungsi secara normal jika terus-menerus dalam keadaan tension

Kekuatiran tidak selalu buruk. Bila tidak ada kekuatiran, kehidupan dapat menjadi membosankan, tidak efisien dan tidak banyak kegembiraan. Kekuatiran memotivasi seseorang dan menambah semangat dalam kehidupan. Beberapa pengaruh dari enxiety ${ }^{10}$ antara lain:

a. Reaksi-reaksi physical

Tentunya setiap orang ketika mengalami kuatir reaksi-reaksi physical berbeda-beda. Ada yang berupa sakit kepala, gangguan pada perut, sesak nafas, tidak ada nafsu makan, perasaan kuatir, cemas, gelisah, dan takut yang muncul secara bersamaan dan biasanya diikuti dengan naiknya rangsangan pada tubuh, yang menggejala dalam bentuk "jantung berdebardebar, keringat dingin, “.

b. Reaksi-reaksi bersifat kejiwaan

c. Reaksi-reaksi untuk mempertahankan diri

Bila kekuatiran berkembang, kebanyakan orang secara tidak sadar, bergantung pada tingkah laku dan pemikiran yang menghilangkan kesakitan dari kekuatiran dan menjadi lebih mudah menutupinya.

d. Reaksi-reaksi spiritual

Kekuatiran dapat memotivasi kita untuk mencari pertolongan ilahi yang ada kalanya kita menganggap remeh, tetapi terbukti bahwa banyak orang berbalik pada Allah pada waktu mereka menghadapi tekanan-tekanan kejiwaan.

\section{Intimacy}

Menurut Stemberg ada tiga teori tentang segitiga cinta. Segitiga itu mengandung: gairah (passion). Gairah adalah elemen motivasional yang didasari oleh dorongan dari dalam diri yang bersifat seksual dan komitmen adalah elemen cognitive berupa keputusan untuk secara seimbang dan tetap menjalankan suatu

${ }_{9}^{9}$ Aaron T. Beck, Anxiety Dirorders and Phobia A Cognitive, (America: Basic Books and A Division of harperCollinsPublishers, 1985), 88-94.

10 Yakub Susabda, Pastoral Konseling Jilid 2, (Malang: Gandum Mas, 2003), 32 
kehidupan bersama ${ }^{11}$ serta komponen keintiman (intimacy). Dari ketiga jenis segitiga cinta di atas, penulis hanya membahas tentang intimacy.

Intimacy melibatkan dua orang yang saling membuka dirinya yang paling dalam. Mereka masuk dalam kehidupan emosional, intelektual, sosial, fisik, dan spiritual yang satu ke dalam yang lain dan sebaliknya. ${ }^{12}$ Kehidupan intimacy disertai dengan perasaan kasih dan percaya sehingga kita membuka diri tanpa kuatir. ${ }^{13}$ Hal ini ditegaskan oleh Frank bahwa,

"intimacy dengan pasangan adalah suatu ikatan elemen emosi, yang di dalam terdapat kehangatan, kepercayaan (trust) dan keinginan untuk membina hubungan, karena ada tujuan yang ingin dicapai yaitu membicarakan secara bersama-sama tentang masalah-masalah sulit yang terjadi dan bagaimana jalan keluar yang ditempuh,"14

sehingga menurut Anne bahwa ada rasa nyaman dan perasaan sakit yang dialami dapat teratasi dengan baik. ${ }^{15}$ Ciri-cirinya antara lain,yaitu seseorang akan merasa dekat dengan seseorang, senang bercakap-cakap dengannya sampai waktu yang lama, merasa rindu bila lama tidak bertemu dan ada keinginan untuk bergandengan tangan atau saling merangkul bahu. ${ }^{16}$

Jadi arti dari intimacy adalah suatu hubungan yang mendalam antara kedua pasangan sehingga mereka dapat membuka diri tanpa ada perasaan takut agar apa yang diharapkan bersama dalam hubungan tersebut dapat bertumbuh dengan sehat.

Apakah dalam menjalani kehidupan sebagai suami istri, intimacy semakin hari bertambah atau berkurang? Ataukah berkurang intimacy? Jika terjadi kegagalan dalam berintimacy atau tidak menciptakan seperti pada awalnya jatuh cinta dan berpacaran, maka perlunya ada pengoreksian kembali dalam hubungan dan saling memaafkan satu dengan yang lain serta belajar bagaimana caranya supaya terjadi intimacy seperti pada awalnya. Hal ini tidak mudah oleh karena setiap pasangan memiliki keegoisan yang susah diruntuhkan, tetapi jika ada komitmen dan bertekat untuk lebih baik dalam berintimacy maka ada harapan.

Membina keakraban merupakan suatu proses dan intimacy itu berubah-ubah, tidak statis. ${ }^{17}$ Proses untuk tetap memiliki keintiman adalah komunikasi. Bagian akan lebih dijelaskan pada topik yang membicarakan tentang komunikasi.

Intimacy tidak dipupuk dengan percakapan yang dangkal, misalnya mengatakan kepada pasangan bahwa kita makan di rumah atau di luar malam ini? Atau juga

11 Menurut Strenberg, setiap komponen itu pada setiap orang berbeda derajatnya. Ada yang hanya tinggi di gairah, tetapi rendah pada komitmen, sedangkan cinta yang ideal adalah apabila ketiga komponen itu berada dalam proporsi yang sesuai pada suatu waktu tertentu. Misalnya pada tahap awal hubungan, yang paling besar adalah keintiman. Setelah keintiman berlanjut pada gairah yang lebih besar (dalam beberapa budaya) diserta dengan komitmen yang lebih besar, misalnya melalui perkawinan

12 Jurnal of Family Psychology, October 2008, Vol. 22, no. 5, 659-666

13 Gary Chapman, Five Signs of a Functional Family, (Batam, Interaksara, 2000), 48-50.

14 Frank D. Cox, Human Intimacy, (United States: West Publishing Company, 1987), 162.

3.

15 Anne Wilson Schaef, Escape from Intimacy, (New York: Harper and Row, Publishers, 1989),

${ }^{16}$ Menurut Anne ini merupakan intimacy yang benar karena ada proses yang terus bertumbuh yang tidak terbatas waktu. Dalam proses tersebut akan saling mengenal dan dikenal dan memerlukan keterbukaan dan ada kemauan dari pribadi masing-masing, 136.

17 Gary, 53-54 
dengan kalimat lain 'jam berapa saya harus jemput anak-anak'? Intimacy berakar dalam berbagi nafsu, emosi, pikiran, dan pengalaman, keinginan-keinginan dan frustrasi-frustrasi kita. Ada beberapa sebab yang dikemukakan oleh Gary ${ }^{18}$ bahwa mengapa tidak ada intimacy, yaitu:

a. Kita tidak membicarakan perasaan kita adalah karena kita tidak lagi mengenalnya. Untuk satu dan lain alasan, ada di antara kita yang dilatih untuk menyangkal perasaan-perasaan kita, contohnya pada waktu kecil ketika kita menangis kita diminta oleh orangtua supaya jangan menangis.

b. Karena kita takut akan respon dari pasangan kita, yaitu kita takut janganjangan ia mengritik perasaan kita.

c. Karena mereka tidak pernah melakukan di masa lalu. Mereka dengan mengatakan bahwa perkawinan kami baik, sehingga mengapa perlu mengutarakan perasaan-perasaan. Orang yang mengatakan demikian biasanya karena latar belakang keluarganya tidak pernah demikian sehingga merasa asing.

d. Karena tidak mau membebani perasaan suami atau istri dengan pergumulan emosionalku.

Yang menjadi perhatian dalam intimacy adalah komunikasi dan saling menerima kelebihan dan kekurangan dengan komitmen untuk lebih baik lagi dalam intimacy. ${ }^{19}$

\section{Communication}

Komunikasi menurut Virginia Satir adalah "interaction" or "transaction". Comunication also includes all those symbols and clues used by persons in giving and receiving meaning. ${ }^{20}$ Menurut Les dan Leslie Parrott, bahwa di dalam intimacy perlu ada komunikasi. ${ }^{21}$ Dalam kaitannya dengan intimacy, maka komunikasi penting untuk membangun hubungan, kerena jika tanpa komunikasi maka sebagai suami atau istri tidak akan mengetahui akan apa yang menjadi isi hati masing-masing dan itu akan menimbulkan masalah. Hal ini ditegaskan oleh Klemer bahwa,

"Failure to communicate because of different word connotations it is not uncommon. But communication more often fails because of one's inability to communicate genuine attitudes and meanings - with or without words. In fact, words are sometimes unimportant. It is possible to say "I hate you" so lovingly that the person addressed recognizes almost at once that this is not an expression of of hostility bt rather one of tenderness. On the other hand, as many longtime husband and wives know, it is possible to say "I love you" in such a flat monotone that it expresses nothing $22 . "$

\footnotetext{
18 Gary, 54-57

${ }^{19}$ Hal ini juga dikatakan oleh Robert Sternberg Parrott bahwa cinta itu dapat dibagi melalui tiga bagian yaitu passion, intimacy and commitment. Les Parrott dan leslie Parrott, Saving Your Marriage Before it Starts, (Michigan: Zondervan, 1995), 33.

20 Virginia Satir, Conjoint Family Therapy, (California: Science and behavior books, 1983), 79

${ }^{21}$ Les dan Leslie Parrott, Selamatkan Pernikahan Anda Sebelum Pernikahan itu Dimulai,

${ }^{22}$ Richard H. Klemer, Mariage and Family Relationship, (New York: Harper and Row Publishers, 1970), 202.
} (Jakarta: Immnuel, 2007), 35 
Menurut Les dan Leslie Parrott, komunikasi yang baik adalah "built first on who you are and only later on what you do."23, dan menurut mereka komunikasi yang penuh sukacita dan pernikahan yang solid meliputi:

(a) Warmth, yaitu suatu sikap untuk menerima pasangan dengan kehangatan melalui perasaan sentuhan dengan penuh sukacita dan kebahagiaan; hal ini ditegaskan juga oleh Parrot bahwa komunikasi yang sukses berdasarkan akan pengenalan diri sendiri juga pasangan dimana setiap pasangan memiliki sifat kehangatan, ketulusan dan empati. Parrott berpendapat bahwa dengan adanya kehangatan pasangan akan lebih merasa rileks, bebas, damai, percaya diri, dapat mengundang anugerah Allah masuk dalam hidup pernikahan dan menghentikan pola pernikahan yang sulit terpahami dan pernikahan yang tidak sehat yang selalu mencari kepuasan diri. Melalui ketulusan menghasilkan kepercayaan dan melalui empati pasangan akan merasa dimengerti dan dipahami.

(b) genuineness,yaitu suatu sikap yang iklas (tidak dibuat-buat) yang dengan ekspresi melalui suara, prilaku yang tidak kelihatan, melalui mata dan gerakan tubuh;

(c) empathy, yaitu merupakan sesuatu yang dibangun untuk memperkuat perkawinan karena itu dapat diikat melalui pemikiran dan hati ${ }^{24}$. meliputi:

Bagi Les dan Leslie ${ }^{25}$ peraturan-peraturan dalam suatu komunikasi yang sukses

1. make 'I" statements, not 'you' statements;

2. practice reflecting listening;

3. understand and accept the differences between men and women;

4. apologize when necessary;

5. communicate through touch.

Komunikasi yang baik merupakan suatu hal yang sangat diperlukan oleh setiap pasangan yang menginginkan akan relasi yang sehat dan harmonis. Bagi Parrot melalui komunikasi yang efektif pasangan semakin bertumbuh dan menjadi dirinya sendiri tanpa menggunakan akan topeng, komunikasi juga merupakan proses (verbal dan non verbal) berbagi informasi dengan pihak lainnnya agar pasangan/lawan bicara memahami apa yang kamu katakan. Susabda dkk berpendapat bahwa melalui komunikasi Kristus hadir dan berkarya dalam hubungan pernikahan tersebut dan masing pasangan dapat merasakan keterlibatan-Nya ${ }^{26}$.

Dapat disimpulkan bahwa komunikasi mempunyai peran yang sangat luas dalam kehidupan suatu pernikahan. Komunikasi merupakan gerbang untuk mengenal dunia lain dari seseorang individu, namun apabila salah satu pasangan sulit berkomunikasi maka sedikit demi sedikit dapat menghancurkan pernikahan tersebut, oleh karenanya Montmogomery berkata "quality communication is central to quality

\footnotetext{
23 Les and leslie Parrot, 77.

${ }^{24}$ Les and leslie Parrot, 77-80.

25 Les dan Leslie Parrott, 81.

26 Yakub Susabda dkk, Konseling Pranikah, (Bandung; Mitra Pusaka, 2005), 60.
} 
marriage".27 Parrot juga berpendapat kemampuan pasangan untuk berkomunikasi adalah penunjang bagi pernikahan yang mantap dan memuaskan. Wright berpendapat bahwa "communication is key to your marriage".Melalui hal ini, penulis menyadari akan pentingnya komunikasi dalam sebuah hubungan dan dampak buruk yang dihasilkan daripada komunikasi tersebut.

\section{Acceptance}

Menurut Les dan Leslie Parrott, bahwa di dalam intimacy perlu ada penerimaan. ${ }^{28}$ Mengapa setiap pasangan perlu menerima satu sama lain? Kita memperhatikan bahwa kedua jenis kelamin dirancang oleh Allah dengan kebutuhan psikologis secara khusus. Masing-masing rentan terhadap yang lain dengan cara-cara yang unik. Jika diperkecil sampai pada hal-hal yang mendasar, maka para wanita mengharapkan pria bersikap romantis, penuh pengertian dan penuh kasih, sedangkan para pria mengharapkan agar wanita bersikap penuh hormat, mendukung dan setia. Kebutuhan ini tertanam dalam kepribadian manusia (bndk. Kej. 2:18). Jadi Allah menciptakan laki-laki dan perempuan untuk menyatu secara emosional dan seksuil.29

keluarga yang harmonis yaitu keluarga yang terus-menerus mengalami perubahan hidup dan bertumbuh lebih sehat. Hal ini ditegaskan juga oleh Sawitri bahwa,

"Cinta sejati menyertakan rasa hormat di antara pasangan, kadar toleransi antar pasangan yang juga cukup bagi penerimaan kekurangan dan kelebihan masingmasing pasangan, dan libatan efeksi yang bukan merupakan manifestasi rasa kesepian yang mendalam pada diri kedua pasangan." ${ }^{30}$

Menurut Neil dan Andrew bahwa acceptance adalah "the act of taking or receiving something offered" or "Favorable reception; approval." 31 Dan menurut Neil dan Andrew terdiri dari komponen, yaitu:

(1) attempt to convert problems into vehicles for intimacy;

(2) derived from helping partners "let go" of the struggle to change each.

Dari penjelasan ini penulis menyadari bahwa betapa pentingnya dapat mengerti pasangan dan menerima dia sebagaimana adanya karena setiap pribadi memiliki karaktersitik yang berbeda-beda dan itu dapat dibentuk dari berbagai hal, yaitu budaya pendidikan, latar belakang social, suku ras dan pola asuh orang tua.

\section{Pengaruh anxiety terhadap intimacy dengan pasangan}

Dari penjelasan di atas, maka penulis memperhatikan ada beberapa pengaruh anxiety terhadap intimacy dengan pasangan, yaitu: 2005), 26.

27 Sawitri S.Sadarjoen, Pendampingku Tak seperti Dulu Lagi, (Jakarta; Penerbit Buku Kompas,

28 Les dan Leslie Parrott, Selamatkan Pernikahan Anda Sebelum Pernikahan itu Dimulai, (Jakarta: Immnuel, 2007), 34

29 James Dobson, Panduan Lengkap Kehidupan Pernikahan dan Kelurga, (Batam: Gospel Press, 2004), 532-533. 2005), 86.

30 Sawitri Supardi Sadarjoen, Pendampingku Tak Seperti Dulu Lagi, ( Jakarta: Buku Kompas,

31 Neil S. Jacobson and Andrew Christensen, Accaptance and Change in Couple Therapy, (London: Norton and Company, 1998), 12. 
a. Anxiety membuat low communication. ${ }^{32}$ Artinya ada ketakutan untuk intimacy dengan pasangan sehingga kurang dapat berkomunikasi dengan pasangan. Ketakutan karena tidak dapat mengutarakan perasaan dan takut tidak dapat menerima apa yang diutarakan. Disamping itu takut karena ada wanita lain merebut suami ibu $x$ dan juga takut salah dalam pemakaian uang untuk keperluan yang tidak benar

b. Anxiety membuat kurang adanya sentuhan-sentuhan secara fisik. ${ }^{33}$

c. Anxiety membuat adanya withdrawal, sehingga tidak sepenuhnya mengetahui dan menemukan pribadi dalam berintimacy. ${ }^{34}$ Disamping itu self esteem tidak didapatkan dari orang lain dan terpisah dari lingkungan sosialnya terutama ibu x dengan keluarga dari pihak suaminya.

d. Anxiety membuat tidak terjadi intimacy dengan baik menunjukan bahwa setiap pasangan memiliki masalah dan menunjukkan bahwa adanya kurang dewasa dalam hubungan ${ }^{35}$ hal ini menurut Klemer ${ }^{36}$ bahwa akibatnya tidak ada kemampuan dalam berkomunkasi dengan baik, disamping itu Sawitri ${ }^{37}$ menambahkan bahwa perlunya toleransi dalam hubungan sehingga bisa menerima satu dengan yang lain.

\section{Kesimpulan}

Anxiety sebagai sesuatu yang terjadi pada siapa saja. Oleh karena setiap pribadi memiliki problema-problema yang tidak jelas bagaimana cara menyelesaikannya dan penyebab-penyebab anxiety serta pengaruh-pengaruh anxiety pada setiap orang pun berbeda.

Dalam sebuah keluarga tentunya mengharapkan agar semakin bertambahnya usia pernikahan semakin ada keharmonisan atau intimacy. Setiap pasangan melakukan berbagai hal atau cara agar sebagai suami istri boleh intimacy, namun cara yang sering dilakukan tidak mendalam tetapi sebagai fenomena luar tanpa langsung pada perasaan-perasaan yang terdalam, akibatnya banyak pasangan yang sudah bertahun-tahun menikah tetapi tidak bertumbuh dengan baik, yaitu tidak mengalami perubahan hidup kedua pasangan bahkan justru berbagai masalah timbul dan semakin rumit dalam menjalani kehidupan sebagai suami istri.

Dalam berintimacy tidak terjadi secara instan tetapi membutuhkan waktu, bahkan seringkali tidak mudah terjadi intimacy oleh karena berbagai faktor yang menghalangi. Hal ini membutuhkan kesiapan hati kedua pasangan untuk saling membantu, jujur, kesabaran dan bersama-sama mau berkomitmen untuk lebih meningkatkan intimacy.

Penulis menjelaskan bahwa hal-hal yang perlu diperhatikan dalam intimacy adalah komunikasi dan penerimaan. Dengan kedua pasang secara jujur dalam mengutarakan perasaan-perasaan maka komunikasi dalam sebuah keluarga dianggap telah berhasil, apalagi disertai dengan penerimaan terhadap berbagai hal yang diungkapkan dan penerimaan tidak secara nyata terhadap setiap sikap.

\footnotetext{
32 Junal APA, 2008, pp. 5431.

33 Jurnal of Family Psychology, Feb 2004, Vol. 23(1), 89-103

34 Jurnal APA, Jul 2002, pp. 514.

35 Jurnal APA, May 2000, pp. 5793

36 Klemer, 202

37 Sawitri,86
} 
VOL. 1 NO. 2 EDISI JULI-DESEMBER 2018. ISSN. 262 1-2684

\section{DAFTAR PUSTAKA}

\section{Buku-buku}

Beck, Aaron T., Anxiety Dirorders and Phobia A Cognitive, (America: Basic Books and A Division of harperCollinsPublishers, 1985)

Chapman, Gary, Five Signs of a Functional Family, (Batam, Interaksara, 2000)

Cox, Frank D., Human Intimacy, (United States: West Publishing Company, 1987)

Dobson, James, Panduan Lengkap Kehidupan Pernikahan dan Kelurga, (Batam: Gospel Press, 2004)

Gary, Collin's, R. Christian Counseling, (Melbourne: Word Publishing, 1988)

Glasser, William, Reality Therapi,( New York, Harper and Row, 1965)

Hiltnes, Seward, Constructive Aspects of Anxiety, (New York: Abingdon Press, 1963)

Jacobson, Neil S. and Andrew Christensen, Accaptance and Change in Couple Therapy, (London: Norton and Company, 1998)

Klemer, Richard H., Mariage and Family Relationship, (New York: Harper and Row Publishers, 1970)

Leslie, Les dan Parrott, Ketika Hal-Hal Buruk Terjadi Pada Pernikahan Yang Baik, (Batam: Interaksara, 2002)

Leslie, Les dan Parrott, Saving Your Marriage Before it Starts, (Michigan: Zondervan, 1995)

Menninger, W. Walter, Coping with Anxiety, (London: Jason Aronson, 1996)

Riany, Fanny, Kehidupan Emosi Orang Kristen, (Jakarta: Binawarga, 1997)

Sadarjoen, Sawitri S., Pendampingku Tak seperti Dulu Lagi, (Jakarta; Penerbit Buku Kompas, 2005)

Satir, Virginia, Conjoint Family Therapy, (California: Science and behavior books, 1983)

Schwarts, Marty Ann, Marriages and Famies, (USA: New Jersey, 1997)

Schaef, Anne Wilson, Escape from Intimacy, (New York: Harper and Row, Publishers, 1989)

Susabda, Yakub Pastoral Konseling Jilid 2, (Malang: Gandum Mas, 2003)

Susabda, Yakub dkk, Konseling Pranikah, (Bandung; Mitra Pusaka, 2005)

\section{Jurnal}


VOL. 1 NO. 2 EDISI JULI-DESEMBER 2018. ISSN. 262 1-2684

Jurnal of Family Psychology, Feb 2004, Vol. 23(1), 89-103

Jurnal APA, Jul 2002, pp. 514.

Jurnal APA, May 2000, pp. 5793

Jurnal of Family Psychology, October 2008, Vol. 22, no. 5, 659-666

Jurnal APA, 2008, pp. 5431 